\title{
A RELAÇÃO \\ GRAMÁTICA-TEXTO \\ NO ENSINO DE LÍNGUA \\ PORTUGUESA: \\ DA LINGUÍSTICA \\ APLICADA À \\ DIDÁTICA \\ DA LÍNGUA
}

\section{LA RELACIÓN GRAMÁTICA-TEXTO EN LA ENSEÑANZA DE LA LENGUA PORTUGUESA: DE LA LINGÜÍSTICA APLICADA A LA DIDÁCTICA DE LA LENGUA}

\author{
THE GRAMMAR-TEXT RELATIONSHIP IN PORTUGUESE LANGUAGE TEACHING: FROM \\ APPLIED LINGUISTICS TO DIDACTICS OF THE LANGUAGE
}

Marcos Bispo*

Universidade do Estado da Bahia

RESUMO: Este texto teve como objetivo analisar a relação gramática-texto na arquitetura da Língua Portuguesa delineada na BNCC. Para isso, confrontou as propostas da abordagem cientificista da relação entre gramática e texto no ensino de Língua Portuguesa desenvolvidas no âmbito da linguística aplicada com a proposta didática da pedagogia das competências apresentada na BNCC. As análises demonstraram que, nas propostas da linguística aplicada, predomina um olhar fragmentário, em razão do pluralismo teórico desarticulado, enquanto, na BNCC, a relação gramática-texto é compreendida de forma global, num continuum que envolve o desenvolvimento de habilidades e competências necessárias ao pleno exercício da cidadania.

PALAVRAS-CHAVE: Didática da língua. Gramática e texto. Linguística aplicada.

RESUMEN: Este texto tuvo como objetivo analizar la relación gramática-texto en la arquitectura de la lengua portuguesa descrita en la BNCC. Para esto, enfrentó las propuestas del enfoque científico de la relación entre gramática y texto en la enseñanza de la Lengua Portuguesa desarrolladas en el ámbito de la lingüística aplicada con la propuesta didáctica de la pedagogía de las

\footnotetext{
* Professor Adjunto na Universidade do Estado da Bahia, onde atua no Departamento de Linguística, Letras e Artes e no Programa de Pós-Graduação em Estudos de Linguagens - PPGEL. Líder do grupo de pesquisa Epistemologias em Didática doPortuguês-EDIPO.E-mail: mabispo@uneb.br
} 
competencias presentada em la BNCC. Los análisis mostraron que, en las propuestas de la lingüística aplicada, predomina una mirada fragmentaria, debido al pluralismo teórico desarticulado, mientras que, en la BNCC, la relación gramática-texto se entiende de manera global, en un continuo que involucra el desarrollo de habilidades y competencias necesarias al pleno ejercicio de la ciudadanía.

PALABRAS CLAVE: Didáctica de las lenguas. Gramática y texto. La lingüística aplicada.

ABSTRACT: This text aimed to analyze the grammar-text relationship in Portuguese language architecture outlined in the BNCC. For that, it confronted the proposals of the scientific approach of the relationship between grammar and text in the teaching of Portuguese Language developed in the scope of applied linguistics with the didactic proposal of the pedagogy of competences presented in the BNCC. The analyzes showed that, in the proposals of applied linguistics, a fragmentary view predominates, due to the disjointed theoretical pluralism, whereas, in BNCC, the grammar-text relationship is understood globally, in a continuum that involves the development of necessary skills and competences to the full exercise of citizenship.

KEYWORDS: Didactics of the language. Grammar and text. Applied Linguistics.

\section{INTRODUÇÃO}

Nas ciências humanas, em que predomina o paradigma interpretativista, o pluralismo teórico é visto como uma riqueza por tornar possível uma multiplicidade de abordagens sobre a complexidade dos fenômenos humanos. Com efeito, seria um equívoco reduzir o estudo da vida social a leis universais advindas de um único modelo teórico, dadas as dimensões psicológicas, históricas, econômicas, socioculturais e políticas que a constituem. Nesse sentido, a diversidade de paradigmas de investigação ou teorias sociais oferece possibilidades de estudos de objetos variados e sob diferentes enfoques, que podem apresentar visões convergentes ou divergentes.

Por outro lado, o pluralismo teórico pode ser problemático, quando se trata de utilizar os conhecimentos científicos na resolução de problemas sociais, visto que as teorias ou adotam uma abordagem fragmentária da realidade, estudando objetos devidamente delimitados, ou adota um único paradigma de descrição e explicação do todo social. Nesses casos, como escolher entre modelos teóricos concorrentes aquele que produzirá os melhores resultados? A escolha deve privilegiar critérios científicos ou políticos? Em geral, a seleção das teorias para resolver questões práticas da vida pública obedecem a critérios políticos, o que acarreta uma tomada de posição quanto às formas de apropriação dos conhecimentos científicos, em função das relações que eles manterão com os outros saberes de determinado contexto. Tal apropriação implicará não apenas em transformações relativas à natureza dos conhecimentos da ciência como também de seu modo de organização. Nesse sentido, esses conhecimentos passam a constituir um compósito complexo de saberes que não mais admite a lógica da fragmentação que lhes deu origem.

Essa breve digressão é importante para contextualizar as controvérsias que perpassam o ensino de gramática no Brasil. De um lado, o pluralismo teórico da linguística, caracterizado por uma abordagem fragmentária, descritiva, portanto, antinormativa, critica severamente as bases epistemológicas da gramática tradicional, fazendo-a parecer um objeto sem utilidade para o ensino. Do outro, as recentes políticas educacionais que, mesmo diante dos conhecimentos e críticas produzidos pelas diversas teorias linguísticas, insistem em manter a gramática normativa como um objeto importante do ensino de linguagem.

Em meio a essa divergência multiplicam-se as propostas de ensino de gramática (descritiva, reflexiva, contextualizada, produtiva), elaboradas por linguistas de diferentes paradigmas teóricos (gerativismo, funcionalismo, sociolinguística educacional, linguística textual, teoria enunciativa, linguística aplicada), sem o devido diálogo com as orientações curriculares oficiais dos Parâmetros Curriculares Nacionais (PCN), publicados em 1997, e da Base Nacional Comum Curricular (BNCC), publicada em 2018, documentos orientados pela pedagogia das competências e por uma nova concepção de conteúdos escolares: habilidades conceituais, procedimentais e atitudinais.

Este texto tem como objetivo confrontar a abordagem cientificista da relação entre gramática e texto no ensino de Língua Portuguesa com a proposta didática da pedagogia das competências apresentada na BNCC. O texto está dividido em três partes. Na 
primeira, são apresentados os fundamentos epistemológicos das propostas oriundas da linguística aplicada. Aqui, esta designação é tomada em sentido lato, seguindo a distinção feita por Santos (2019) entre linguística aplicada lato senso, relativa a qualquer tentativa de aplicação da linguística teórica, e linguística aplicada stricto senso, que se refere a um campo institucionalizado de investigação sobre problemas sociais envolvendo a linguagem (MOITA LOPES, 1996, 2006; KLEIMAN e CAVALCANTI, 2007). $\mathrm{Na}$ segunda parte, situo a BNCC e a didática da língua no contexto da pedagogia das competências. Finalmente, analiso a relação gramática-texto na arquitetura da Língua Portuguesa delineada na BNCC.

\section{TEXTO E GRAMÁTICA NA LINGUÍSTICA APLICADA AO ENSINO}

Um olhar cuidadoso nos documentos oficiais de orientação curricular brasileiros, PCN e BNCC, revela com muita nitidez que, para além da presença de conceitos que remetem a uma ou outra teoria linguística, existem muitas divergências entre a perspectiva de ensino de linguagem neles assumida e as propostas da linguística aplicada ao ensino de gramática e texto na educação básica. Como explicar tal descompasso?

A falta de compreensão sobre como se dá a relação entre ciência e política está na base da militância de muitos linguistas aplicados por um ensino de gramática antinormativo, com foco no modelo descritivista, que encontra sua contraparte pedagógica sob a forma de propostas orientadas para o ensino reflexivo, contextualizado e produtivo de gramática. O descritivismo se orienta pelo princípio de que toda língua natural se compõe de um conjunto de variedades igualmente legítimas e que, por isso, não podem ser submetidas a juízos de valor.

Dada a posição do descritivismo em relação às normas sociais, podemos classificá-lo como um tipo de naturalismo, seguindo a argumentação de Santos (2019), para quem não é que todas as formas de descritivismo linguístico rejeitem a normatização da linguagem, mas todas elas recusam a possibilidade de tais normas contrariarem os usos efetivos (naturais) dos falantes. $\mathrm{O}$ naturalismo desse posicionamento se manifesta claramente através do conceito de gramática internalizada, ou seja, o conhecimento mental que o falante tem de sua língua, e que constitui o objeto da gramática descritiva. O naturalismo, portanto, é o fundamento do relativismo linguístico, bem expresso nas palavras de Possenti (2003, p. 52): "é preciso dizer, com todas as letras, que todas as variedades [linguísticas] são boas e corretas, e que funcionam segundo regras tão rígidas quanto se imagina que são as da língua clássica dos melhores autores"'.

A tese de Possenti apresenta contradições internas que serão chamadas aqui de paradoxo descritivista, cujo funcionamento afeta tanto a vertente teórica quanto aplicada da linguística. Do ponto de vista teórico, é preciso destacar que não cabe a uma ciência descritiva fazer afirmações valorativas sobre as variedades linguísticas, a exemplo do que faz Possenti quando afirma que todas as variedades são boas e corretas. A rigor, a descrição deve restringir-se a demonstrar como tais variedades se caracterizam e funcionam.

O tratamento de valores caberia apenas em uma abordagem de natureza política, onde o paradoxo descritivista também se revela problemático, dado seu viés aplicacionista. Um exemplo disso está na tese de que não há erros e acertos em matéria de língua, mas usos adequados ou não às situações comunicativas, uma vez que, contrariando o postulado de que todas as variedades são boas e corretas, acaba por admitir que a sociedade pode estabelecer regras sobre a (não)aceitação de determinados usos em situações comunicativas específicas.

Contudo, o ápice do paradoxo descritivista se materializa na dicotomia entre norma padrão (escrita) e norma culta (falada) postulada pelos linguistas. Na verdade, ela é duplamente paradoxal. Primeiro, porque ratifica o caráter normativista de uma ciência que se autoproclama descritiva. Segundo, porque se propõe a "descobrir" uma norma culta natural sem considerar que o próprio qualificativo dessa norma só faz sentido quando situado num sistema de valores sociais.

O problema se agrava quando nos deparamos com o fato de que uma ciência descritiva estabeleceu, recorrendo a critérios sociais, quem seriam os falantes cultos da língua: pessoas com nível superior completo, parâmetro estabelecido pelo Projeto Nurc. Parece 
ter escapado aos linguistas que, na relação opositiva em que todo sistema de valores se ampara, todos aqueles que não se encaixam nos critérios que definem o falante culto serão, automaticamente, classificados como incultos.

É possível afirmar que as contradições da teoria linguística aqui mencionadas decorrem de tentativas de aplicação direta dos conhecimentos científicos, ignorando que a vida social e suas práticas têm regras próprias de funcionamento. Como bem assinalou Bourdieu (2008), na vida social, o que está em questão não é a capacidade natural do indivíduo para falar uma língua, mas a de usar a língua socialmente legitimada nas situações que a exigem. Logo, não parece adequado descrever regras naturais da língua falada por grupos específicos e tomá-las como referências para a escrita, à revelia dos processos sociais que envolvem as práticas de letramento. É preciso, portanto, compreender as funções das normas linguísticas na organização da sociedade para que sejam tomadas decisões políticas sobre o papel da ciência no desenvolvimento das políticas educacionais.

É comum ouvir de muitas pessoas da área de Letras que nenhum linguista é contra o ensino de gramática. No entanto, quando os linguistas fazem esse tipo de afirmação podem estar dizendo coisas muito diferentes entre si. Bagno (2011), por exemplo, afirma, categoricamente, que "não se deve ensinar norma padrão na escola" (p. 31) e que "as gramáticas prescritivas não podem servir de material pedagógico" (p. 104). Em trabalho mais recente, defende que a escola não deve comprometer-se com o ensino de nenhuma norma, nem culta nem padrão (BAGNO, 2019).

Perini (2010) afirma que "estudar gramática não leva e nunca levou ninguém a desenvolver suas habilidades de leitura, escrita ou fala, nem sequer seus conhecimentos práticos do português padrão escrito” (p. 30). Para ele, "[...] a gramática é uma disciplina científica, tal como a astronomia, a química, a história ou a geografia; ela deve ser estudada porque é parte da formação científica dos alunos" (p. 30). Ou seja, em sua avaliação, o estudo da gramática não deve ter sentido prático.

Há, porém, aqueles que defendem o ensino sistemático de gramática e que reconhecem seu papel na estruturação textual. Nesse caso, o pluralismo teórico da linguística faz emergirem propostas com diferentes concepções de gramática, metodologias de ensino e compêndios de gramáticas científicas. O resultado disso é que estamos sempre diante de olhares parciais sobre a linguagem, que obedecem aos princípios teórico-metodológicos de paradigmas conflitantes entre si, portanto, incapazes de serem todos diretamente transferidos para o ensino.

O conflito paradigmático mais importante se refere à oposição entre as abordagens tradicional e científica da gramática, caracterizado por uma profunda revisão teórica, metodológica e explicativa da gramática tradicional pela linguística. Com efeito, após toda essa crítica, fica difícil dizer que ela terá alguma utilidade teórica ou prática.

Para suprir o vazio deixado pela desconstrução da gramática tradicional, vários linguistas se empenharam na elaboração de gramáticas mais coerentes do ponto de vista científico (PERINI, 2010; BAGNO 2011; CASTILHO, 2010; CASTILHO e ELIAS, 2012; NEVES, 2000). Porém, Faraco e Vieira (2016, p. 293) chegaram às seguintes conclusões após analisarem sete gramáticas contemporâneas do português (cinco delas de linguistas):

As sete gramáticas contemporâneas do português analisadas abraçam diferentes objetivos e objetos, se valem de referenciais teóricos particulares, selecionam temas e conteúdos específicos a seus propósitos e se organizam de maneiras bastante singulares, de modo que a própria palavra "gramática" dos títulos parece não ter um referente claramente identificável.

Dito de outra forma, se o termo "gramática", em princípio, identifica um livro que tem como assunto uma apresentação abrangente de elementos constitutivos de uma língua ou de uma variedade dessa língua, o conteúdo de cada um dos nossos sete livros é tão amplo e diverso que não á absurdo nos pormos, ao cabo da leitura, a pergunta: o que é, afinal uma gramática?

No campo científico naturalista, a gramática toma como referência de descrição algum recorte de determinada variedade de língua falada (nunca uma variedade em sua totalidade nem o conjunto de todas as variedades). Como destacam Faraco e Vieira, o pluralismo teórico da linguística faz com que cada gramática elaborada segundo a racionalidade científica adote formas tão diversas a ponto de a noção de gramática ficar descaracterizada e inviabilizada como referência para o ensino e as práticas sociais de 
linguagem em sociedades letradas, sobretudo porque as gramáticas científicas compartilham a recusa em descrever a modalidade padrão escrita. Sendo assim, não se verifica, no campo científico, nenhuma relação entre gramática e texto.

No contexto pedagógico, algumas das funções da gramática são: i) apresentar uma visão global da estrutura da língua padrão, seu objeto de descrição, de acordo com uma racionalidade particular, utilizando-se de uma terminologia própria e geralmente unificada; ii) servir de fundamento para a elaboração de propostas curriculares e elaboração de materiais didáticos. Embora se trate de um dispositivo descritivo-normativo da língua oficial que rege o estilo de linguagem empregado em diversos gêneros textuais que circulam nas mais diversas esferas sociais, a gramática não se confunde com o texto, de maneira que seu conhecimento não garante, ipso facto, o conjunto das capacidades envolvidas na produção de textos. No entanto, considerando que o estilo é um dos elementos definidores da natureza dos gêneros, conforme a definição de Bakhtin (2016), parece evidente que o conhecimento gramatical exerce um papel importante no desenvolvimento de habilidades textuais.

A rigor, no modelo científico, o mais adequando seria falar em estudo e não em ensino da gramática, como propõe Bagno (2019), dado que, na perspectiva descritiva não caberia ensinar a língua falada, seu objeto de estudos. Assim, as metodologias de ensino seriam substituídas pelas metodologias de pesquisa utilizadas no campo do gerativismo (PILATI, 2017), do funcionalismo (CASTILHO; ELIAS, 2012), da sociolinguística (ZILLES; FARACO, 2015). Nessas propostas, a ideia de ensinar a língua está associada a uma concepção normativista, em tudo contrária ao descritivismo.

Ao lado das propostas pedagógicas elaboradas por especialistas em paradigmas teóricos específicos, como os citados no parágrafo anterior, há outras como as de Antunes (2014), Mendonça (2006) e Vieira (2018), que, compreendendo os limites dessas abordagens, propõem modelos inter ou multidisciplinares. No entanto, esses agrupamentos disciplinares enfrentam desafios para a harmonização adequada de teorias e métodos. Vejamos esses desafios.

Na proposta de Antunes (2014, p. 46), a gramática contextualizada é definida como "uma perspectiva de estudo dos fenômenos gramaticais, ou uma estratégia de exploração do componente gramatical do texto, tomando, como referência de seus valores e funções, os efeitos que esses fenômenos provocam nos diversos usos da fala e da escrita". Trata-se, portanto, não de uma concepção teórica de gramática, mas de uma metodologia de ensino.

A definição sugere que o estudo dos fenômenos gramaticais deve-se dar a partir de seu funcionamento no texto. Não fica claro, porém, se os fenômenos gramaticais deverão ser definidos previamente, considerando os objetos de uma ou mais teorias linguísticas, ou se todos os elementos do texto serão estudados a cada vez que um texto é apresentado aos estudantes, independentemente do período da escolaridade em que se encontrem.

Embora assuma uma concepção interacionista de linguagem, a autora defende a mesma concepção descritivista de gramática que Perini (2010), para quem essa disciplina não desempenha nenhum papel no desenvolvimento de habilidades de leitura e escrita:

\footnotetext{
No que concerne ao estudo mais específico da gramática, sobretudo quando se pretende explicitar seu funcionamento, a escola deveria adotar uma perspectiva científica, de criteriosa observação, análise e sistematização. Isso a levaria, primeiro, a concentrar-se na multiplicidade e diversidade de usos que, habitualmente, acontecem e, segundo, a desviar-se da postura marcadamente prescritiva, pela qual só os erros e os respectivos acertos são objetos de consideração. Além disso, não seriam atribuídas à gramática funções que não lhe competem. Como propõe Perini [...] (ANTUNES, 2014, p. 63)
}

Essa concepção de estudo da gramática se assemelha também à defendida pela sociolinguística educacional, que busca transferir para o ensino os pressupostos teórico-metodológicos da sociolinguística variacionista, como se verifica nas palavras de Antunes (2014, p. 111):

Em geral, ensinamos regras de sintaxe, por exemplo, repetindo o que está nos manuais de gramática, sem qualquer consideração à possibilidade de essas regras já não estarem vigorando entre os falantes mais escolarizados e em situações de mais monitoramento. As regras são ditadas como se valessem por elas mesmas, 
sem que os alunos sejam alertados para a possibilidade de que tais regras podem já não estar valendo ou podem valer apenas em um ou outro contexto.

A sociolinguística educacional se baseia na tese de que as distâncias entre fala e escrita devem ser superadas pela conformação desta às regras daquela. No entanto, o foco nos aspectos morfossintáticos da variação linguística deixa escapar, por exemplo, relações entre fala e escrita referentes ao nível fonológico (monotongação, síncope, apócope etc.), para as quais não se reivindica uma aproximação entre fala e escrita.

Outro fator problemático envolvendo a forma como a sociolinguística educacional lida com as diferenças entre fala e escrita diz respeito ao caráter exclusivamente sincrônico de sua abordagem, ignorando os usos linguísticos mais recuados no tempo, a exemplo do que ocorre nos textos literários de séculos anteriores. Em contrapartida, como bem observa Santos (2018), a norma padrão não é estática, como faz parecer o discurso maniqueísta de muitos linguistas, mas dinâmica o suficiente para fornecer uma visão pancrônica dos fenômenos gramaticais da modalidade escrita.

Apesar de concordar com essas observações, quando assume o paradigma descritivista da sociolinguística educacional como um dos fundamentos da gramática contextualizada, Antunes (2014) age, contraditoriamente, como se todos os gêneros que circulam nas diversas esferas sociais seguissem ou devessem seguir as mesmas regras da norma culta falada.

A proposta da gramática contextualizada se completa com algumas contribuições da linguística textual, relacionadas, principalmente, a temas como a referenciação e aos operadores lógico-discursivos. Contudo, ao apresentar demonstrações de como fazer a análise contextualizada, apenas a linguística textual aparece como teoria fundamental, sem qualquer menção à concepção interacionista da linguagem, ao estudo científico da gramática ou ao descritivismo da sociolinguística educacional. Do ponto de vista didático, a metodologia proposta não prevê formas de organização e progressão dos conteúdos ao longo dos anos de escolaridade

A prática de análise linguística, inicialmente proposta por Geraldi (2003), adotando uma concepção interacionista de linguagem, defende que os textos escritos pelos alunos sejam o ponto de partida para o estudo do papel da gramática na estruturação textual. Sem defender teorias linguísticas ou concepções de gramática específicas, a análise linguística apresenta-se como uma perspectiva metodológica que enfatiza o caráter instrumental dos saberes gramaticais em sua articulação com o texto. Nas palavras do autor, "o objetivo essencial da análise linguística é a reescrita do texto do aluno [...]. O objetivo não é o aluno dominar a terminologia (embora possa usá-la), mas compreender o fenômeno linguístico em estudo” (GERALDI, 2003, p. 74). Em seu modelo, os problemas a serem abordados se referem à estrutura textual, à sintaxe, à morfologia e à estilística.

Discutindo a metodologia com foco no Ensino Médio, Mendonça (2006) amplia o alcance da análise linguística para além da reescrita de textos ao defender que a metodologia necessita de uma sistematização:

[...] nessa etapa da escolarização, não há mais motivo para tratar os fenômenos normativos, sistêmicos, textuais e discursivos de forma intuitiva. Isso é defendido para a abordagem de alguns aspectos no EFI (principalmente) e EFII, quando a meta maior é alfabetizar e letrar, ou seja, levar os alunos à apropriação do sistema de escrita e inseri-los em diversas práticas letradas significativas. Portanto, é preciso que o trabalho com a AL no EM parta de uma reflexão explícita e organizada para resultar na construção progressiva de conhecimentos e categorias explicativas dos fenômenos em análise. (MENDONÇA, 2006, p. 204, grifos da autora)

Como se vê, a autora propõe um ponto de partida diferente do de Geraldi, por entender que há diferenças de objetivos do ensino de língua nos distintos níveis da educação básica, embora lhe falte uma justificativa que ultrapasse a própria análise. Da forma como está posto, a análise se torna um fim em si mesma. Por outro lado, partir de uma reflexão explícita e organizada para garantir uma construção progressiva de conhecimentos linguísticos impõe a necessidade da elaboração de um currículo e de uma terminologia adequada. O problema é que essa sistematização curricular exige a seleção de teorias e métodos advindos do diálogo com as teorias linguísticas e da aprendizagem, algo que não se vê nem na proposta de Geraldi nem na de Mendonça. 
A ausência de fundamentação teórica sistematizada e explícita nas propostas de análise linguística levou Vieira (2018) a classificá-la como uma metodologia instrumental de abordagem da gramática. Na verdade, a autora se ressente da falta de valorização das teorias linguísticas nessa metodologia. Sua proposta de ensino de gramática em três eixos busca superar essa limitação. Para ela, "trata-se de focalizar fenômenos linguísticos como: (i) elementos que permitem a abordagem reflexiva da gramática; (ii) recursos expressivos na construção do sentido do texto; e (iii) instância de manifestação de normas/variedades" (VIEIRA, 2018, p. 52).

Para a autora, esse modelo tem o desafio metodológico de "integrar, sempre que possível, a reflexão linguística aos outros objetivos escolares quanto ao plano textual e à complexidade da variação linguística" (p. 51). Fica evidente que o eixo da reflexão linguística figura como o ponto de partida do ensino de gramática e que os demais só serão contemplados quando possível. Esses pressupostos suscitam três questões importantes: qual o sentido da reflexão linguística quando não é possível relacioná-la com os demais eixos? Faz sentido separar os eixos 1 e 3, como se fosse possível refletir sobre a língua sem considerar as normas e a variação linguística? A proposta apresenta uma organização sistemática e progressiva dos conteúdos gramaticais distribuídas nos três eixos? A resposta a essas perguntas passa pelo conhecimento das características de cada eixo.

O eixo 1, da reflexão gramatical, se inspira na proposta de Franchi (2006), que sugere três atividades escolares com a componente gramatical: a linguística, a epilinguística e a metalinguística. A primeira se refere ao exercício do saber linguístico internalizado das crianças na escola, através de atividades de leitura e produção de textos.

As atividades epilinguísticas consistem num conjunto de práticas voltadas para o próprio conhecimento intuitivo da linguagem, com o objetivo de torná-lo consciente, conforme explica Franchi (2006, p. 94):

[...] nesse jogo de construção e reconstrução dos textos, não se necessita de um conhecimento detalhado nem sofisticado de noções e nomenclaturas gramaticais. Basta recorrer à intuição dos alunos e professores para sua própria língua. Nesse nível de trabalho, não se ainda está necessitando de uma gramática enquanto sistema de noções, mas do conhecimento gramatical interiorizado por todo o falante da sintaxe de sua língua, das regras pelas quais constrói e transforma as expressões em operações conscientes. Em outros termos, basta explorar com sensibilidade o fato de que todos falam português e conhecem as estruturas dessa língua, torná-las explícitas, em uma práxis ativa e dinâmica.

Evidencia-se nas palavras de Franchi uma confusão entre os saberes gramaticais internalizados por todos os falantes de uma língua natural, com base na concepção gerativista/biológica de linguagem, e os conhecimentos gramaticais exigidos para a (re)construção de textos, que se baseiam numa concepção histórico-cultural de linguagem. Ou seja, para Franchi, as regras das modalidades escrita e falada da língua são as mesmas. Como se sabe, uma quantidade considerável das regras da língua escrita diverge dos saberes gramaticais intuitivos que orientam a língua falada, sobretudo em contextos comunicativos mais monitorados.

A atividade metalinguística diz respeito ao trabalho de sistematização gramatical resultante de uma larga familiaridade com os fatos da língua proporcionada pelas atividades epilinguísticas. Conforme a explicação de Vieira (2018), a sistematização metalinguística num quadro intuitivo ou teórico e "permite descrever a linguagem a partir da observação do caráter sistemático das construções repletas de significações” (p. 53). Franchi, tal qual Perini (2010), aproxima a gramática às ciências naturais ao dizer que

Com objetivos muito próximos (similares aos do aprendizado de outras ciências naturais), chega-se assim a uma "teoria gramatical". Quando? Nas últimas séries do primeiro grau? Não tenho muitas razões para responder aqui, mas já se sabe como. Como resultado de uma larga familiaridade com os fatos da língua, como decorrente da necessidade de sistematizar um saber linguístico que se aprimorou e se tornou consciente e com a questão fundamental sempre em mente: a questão da significação, não somente no sentido de uma representação do mundo, mas no sentido também de uma ação pela linguagem sobre os interlocutores, dependente do modo e estilo com que nos servimos dela e de seus múltiplos recursos de expressão. (FRANCHI, 2006, p. 98-99)

Além da vinculação da proposta de gramática reflexiva ao naturalismo e das contradições que o modelo revela ao tentar incorporar a modalidade escrita, outro aspecto a destacar é a incoerência didática em torno do processo de sistematização metalinguística. 
Como fica bem claro no trecho citado, não é possível definir uma teoria gramatical prévia que permita estabelecer a organização e a progressão dos conteúdos gramaticais necessárias para a elaboração de um currículo para a educação básica.

O final da citação de Franchi, ao listar os métodos de construção subjetiva da teoria gramatical, indica que a questão do sentido da linguagem está diretamente vinculada às atividades epilinguísticas e metalinguísticas. Contudo, na proposta de Vieira (2018), a construção do sentido deixa de ser um método da gramática reflexiva para constituir um eixo à parte.

Em sua proposta, o eixo 2, da construção do sentido, deve explorar a relação texto-gramática sob duas perspectivas teóricas: a da gramática funcional e a análise semiolinguística do discurso. É evidente que essas duas teorias não dão conta de todos os aspectos envolvidos na significação dos textos. Em razão disso, é possível que outras teorias como a linguística textual, a pragmática, dentre outras, possam ser incorporadas ao eixo. De qualquer forma, permanece o problema acerca da composição orgânica e progressiva dos conteúdos do eixo e seus fundamentos teóricos. Sobre a relação entre os eixos 1 e 2, é importante destacar que, entre as abordagens intuitivas, próprias do gerativismo, adotadas no primeiro, e funcionalistas ou discursivas, adotadas no segundo, há diferenças inconciliáveis que precisariam ser resolvidas no plano didático.

O eixo 3, da variação e normas linguísticas, parte de uma distinção problemática entre ensino de gramática, compreendida como "regras naturais que nos permitem produzir e interpretar enunciados capazes de significar" (VIEIRA, 2018, p. 55), e ensino de norma padrão, "conjunto de regras linguísticas a serem seguidas para o domínio de estruturas consideradas de prestígio em meios escolarizados, sobretudo em situações formais orais e escritas" (p. 55). Partindo dessa distinção, Vieira defende uma abordagem pedagógica caracterizada pela centralidade das normas cultas como referências de usos reais e que, por isso, deverá ser comparada com os conhecimentos linguísticos intuitivos, com as normas presentes em variados gêneros textuais atuais e com a norma padrão, esta vista como idealizada, arcaica e purista. A metodologia apresentada parece indicar que não faz muito sentido separar os eixos 1 e 3 em blocos diferentes.

Trabalhos desenvolvidos a partir da proposta dos três eixos como os de Chagas (2018) e Souza (2018) demonstram que o modelo idealiza uma abordagem linear, começando o estudo dos fenômenos linguísticos pelo eixo 1 e terminando no eixo 3 . No entanto, como Chagas adverte, não é possível garantir a abordagem tridimensional para todos os conteúdos gramaticais:

Por mais que objetivemos trabalhar com os três eixos ao longo da prática pedagógica, consideramos importante compreender que, em função do fenômeno linguístico tratado, um ou outro eixo pode aflorar com mais facilidade ou possuir menores ou diferentes possibilidades de tratamento. Nesse sentido, entendemos que a concordância verbal, diferentemente de outros fenômenos, possui algumas limitações no que diz respeito ao trabalho com o eixo 2, se forem considerados prioritariamente processos de construção de sentido no plano global ou macroestrutural do texto. (CHAGAS, 2018, p. 65)

A caracterização dos eixos demonstra que cada um deles é orientado por um conjunto específico de concepções teóricometodológicas. Cada um é regido por uma concepção de gramática: gerativa, funcionalista e sociolinguística, respectivamente, todas baseadas no viés naturalista. A rigor, o terceiro eixo não deveria estar separado do primeiro, uma vez que os conhecimentos intuitivos explorados nas atividades epilinguísticas estão diretamente ligados ao funcionamento das normas linguísticas. De igual modo, o segundo eixo consiste em um dos passos metodológicos necessários para a sistematização metalinguística da teoria gramatical, conforme a proposta de Franchi. Da forma como se apresenta, o ensino de gramática em três eixos parece uma tentativa de aglutinar as diversas propostas de ensino de gramática em um único modelo multidisciplinar, formado por blocos que possam garantir a alocação da multiplicidade de disciplinas e paradigmas interessados na aplicação de conhecimentos científicos ao ensino.

Em suma, a proposta tenta pôr ordem ao caos em que se transformou o debate sobre o ensino de gramática no âmbito da linguística aplicada e, consequentemente, na educação básica, ao agrupar esse conjunto de posições, como vimos, nem sempre harmoniosas, em três grandes blocos temáticos. No entanto, a primazia que confere à abordagem naturalista nos estudos gramaticais dificulta a elaboração de uma proposta curricular completa, capaz de fornecer uma imagem global das relações entre gramática e texto. Sem isso, é impossível definir a organização e a progressão dos conteúdos gramaticais ao longo da educação básica. 


\section{DA PEDAGOGIA DAS COMPETÊNCIAS À BNCC}

Enquanto as propostas disciplinares de ensino de gramática dos linguistas especialistas assumem um viés parcial e fragmentário de abordagem, as propostas inter e multidisciplinares tratam o todo como mera soma das partes. Ou seja, como se bastasse reunir teorias com objetos afins em relação aos conteúdos escolares para se construir um modelo didático. As relações entre gramática e texto no ensino vão além da mera questão metodológica em torno do alinhamento a paradigmas científicos ou da contextualização desses objetos em atividades pedagógicas. Envolvem, sobretudo, o desenvolvimento de habilidades e competências para práticas intencionais e socialmente situadas de linguagem.

Parece claro que a linguística aplicada, a despeito das importantes contribuições que tem oferecido ao ensino, mostra-se insuficiente para abordar a relação entre gramática e texto em sua globalidade. Santos (2019) destaca que, no Brasil, a tarefa de elaborar uma imagem global das disciplinas escolares tem sido executada pelos planejadores das políticas educacionais no âmbito do Ministério da Educação e das Secretarias Estaduais e Municipais de Educação. Embora essas instruções curriculares oficiais dialoguem com as disciplinas científicas, não se trata de uma simples aplicação de teorias e métodos científicos na configuração do currículo, mas de um processo de apropriação e reconstrução de saberes que, no contexto das didáticas específicas, recebe o nome de transposição didática externa (PETITJEAN, 2008, ASTOLFI; DEVELAY, 2012).

\subsection{O CURRÍCULO NA PEDAGOGIA DAS COMPETÊNCIAS}

No Brasil, como na maioria dos países ocidentais, assumiu-se a pedagogia das competências como norteadora das políticas educacionais. Por sua vinculação ao mundo laboral, a noção de competência é alvo de resistência de muitos educadores e pesquisadores, sobretudo dos defensores da pedagogia crítica. No plano epistemológico, outros pesquisadores criticam as flutuações teóricas que atravessam as competências, resultando em múltiplas definições do conceito (BRONCKART e DOLZ, 2004; GIMENO SACRISTÁN, 2011), outros criticam as dificuldades de adaptação dessa pedagogia ao contexto escolar (DOLZ e OLLAGNIER, 2004; MÉNDEZ, 2011).

Em todas essas críticas está em jogo o problema da transposição didática (TD). Na formulação inicial de Chevallard (1985), a TD se restringe às disciplinas escolares, não atingindo a perspectiva pedagógica assumida, e explicava os processos ou regras de passagem dos conhecimentos científicos a conhecimentos didáticos. Aqui, a TD será entendida como a passagem dos saberes oriundos de campos disciplinares, da cultura e das práticas sociais ao campo educacional, considerando o papel da educação formal nos processos de desenvolvimento humano necessários à socialização das novas gerações. Nesse sentido, como Zabala e Arnau (2020, p. 5) explicam:

Enquanto, no mundo laboral, o objetivo das competências era identificar o que promovia maior eficiência na realização das tarefas profissionais, a fim de aumentar a produtividade, no mundo educacional a sua introdução se deve à incapacidade manifesta dos alunos de aplicar os conhecimentos aprendidos na escola para resolver seus problemas cotidianos. A partir dessa afirmação se depreende uma opinião que, para muitos, pode ser considerada pelo menos questionável: que a função da escola é preparar para a resolução de problemas cotidianos. Em outras palavras, uma escola que desenvolve todas aquelas competências que permitem que a pessoa responda de maneira adequada aos diferentes problemas e situações da vida, não apenas no campo acadêmico e profissional, mas também, e especialmente, nas esferas pessoal, interpessoal e social. Isto é, uma formação para a vida que se concretiza no desenvolvimento de competências básicas.

Como se vê, a TD das competências não tem qualquer relação direta com práticas profissionalizantes, mas com o sentido dos saberes escolares, que não podem mais ser transmitidos e solicitados em tarefas meramente escolares. Com isso, rompe-se com a educação propedêutica e os saberes passam a ser ensinados e aprendidos para serem utilizados nas mais variadas situações da vida cotidiana. Nesse sentido, as competências direcionam as práticas educativas para o desenvolvimento humano nas esferas acadêmica, profissional, pessoal, interpessoal, cultural e social. No entanto, como argumentam Zabala e Arnau, não é correto falar em utilitarismo, mas em funcionalidade do saber na pedagogia das competências, posto que não existe nenhuma aplicação previamente

Forum lingüístic., Florianópolis, v.18,n.2, p.6196-6213,abr./jun.2021 
definida para os saberes. Trata-se, na verdade, da construção de saberes que poderão ser mobilizados em situações variadas e imprevisíveis da vida cotidiana.

A concepção de competência adotada deve conter os elementos que permitam identificar as teorias e métodos necessários para orientar a elaboração dos referenciais e dos demais elementos que definem a configuração curricular. Não se trata, portanto, de resolver as controvérsias epistemológicas que atravessam a noção de competência, mas de selecionar ou elaborar aquela que melhor se alinha aos objetivos do projeto educacional que se quer implementar.

A BNCC, documento de caráter normativo que, em conformidade com a Lei de Diretrizes e Bases da Educação nº 9.394/96, estabelece o currículo mínimo comum da educação brasileira, seguindo os princípios defendidos por Perrenoud (2013), distribui seu referencial de competências em três grupos: gerais (transdisciplinares), de áreas (pluridisciplinares) e específicas (disciplinares). No documento a competência é definida como "a mobilização de conhecimentos (conceitos e procedimentos), habilidades (práticas, cognitivas e socioemocionais), atitudes e valores para resolver demandas complexas da vida cotidiana, do pleno exercício da cidadania e do mundo do trabalho" (BRASIL, 2018, p. 8) (Grifos acrescidos). Essa compreensão, no contexto da pedagogia das competências, impede que os conteúdos sejam tratados de maneira mecânica, uma vez que, sem desenvolvimento cognitivo, a aprendizagem não se torna significativa. Coube à psicologia da educação a tarefa de elaborar uma nova tipologia dos conteúdos capaz de viabilizar a implementação da educação por competências (COLL et al., 2000; POZO, 2002; ZABALA; ARNAU, 2010).

A pedagogia das competências completa seu quadro teórico com a didática geral e as didáticas das disciplinas. Aqui, convém refutar posições como as de Ghiraldelli Jr. (2006), que concebe a pedagogia como teórica e a didática como meramente técnica ou instrumental. Não há dúvida de que à pedagogia cabe o estabelecimento da perspectiva educacional e a articulação orgânica das ciências da educação com a política e a cultura. Todavia, no plano da política curricular, compete à didática geral elaborar:

i. as teorias dos elementos que constituem a prática de ensino comuns a todas as disciplinas, tais como os objetivos, os conteúdos, os métodos de ensino, os modelos de interação professor-aluno e avaliação, tarefa realizada em constante articulação com as demais ciências da educação.

ii. o referencial de competências trans e pluridisciplinares, tais como se encontram na BNCC, na forma de competências gerais e de áreas.

Já foi destacado aqui que as didáticas específicas, em seu processo de desenvolvimento como disciplinas autônomas, estão reproduzindo a lógica da fragmentação da ciência moderna. Por outro lado, os didáticos são unânimes em reconhecer a relação de suas disciplinas com as prescrições curriculares oficiais. No Brasil, a didática das línguas ainda não existe como campo institucionalizado. Assim, conforme a observação de Santos (2019), os currículos das disciplinas são elaborados pelos planejadores das políticas educacionais, com a participação de especialistas de diferentes áreas.

Em razão dessa lacuna, ainda predomina no campo acadêmico uma abordagem sobre o ensino centrada na transferência dos conhecimentos científicos para o contexto escolar. Consequentemente, prevalece um tratamento fragmentado e, portanto, incapaz de fornecer uma visão global da educação como um processo, ao mesmo tempo, político, cultural e científico. No plano da política curricular, compete às didáticas específicas:

i. Elaborar o referencias de competências de cada disciplina curricular;

ii. Elaborar a estrutura das disciplinas, selecionar os conteúdos (conceituais, procedimentais e atitudinais), relacionando os aspectos pertinentes das ciências da educação e das ciências de referência das disciplinas escolares no contexto da pedagogia das competências;

iii. Organizar e estabelecer a progressão dos conteúdos ao longo dos diferentes níveis de escolarização, considerando as diferentes fases do desenvolvimento sociocognitivo dos estudantes;

iv. Desenvolver pesquisa pedagógica envolvendo a implementação da pedagogia das competências, acompanhando e investigando a adequação da proposta curricular, dos materiais e estratégias didáticas, bem como da interação professor-aluno, tendo em vista o aperfeiçoamento do processo educativo. 


\section{A RELAÇÃO GRAMÁTICA-TEXTO NA PEDAGOGIA DAS COMPETÊNCIAS}

A pedagogia das competências se caracteriza por apresentar uma visão holística do processo educativo. Para isso, precisa promover uma articulação orgânica dos componentes disciplinares que constituem seu projeto curricular, tendo em vista os objetivos políticos da educação em sociedades complexas. Sua fundamentação teórica mobiliza contribuições da ciência política, das ciências da educação (sociologia, filosofia, psicologia, antropologia, didática geral e específicas) e das ciências de referência das disciplinas escolares.

As didáticas das disciplinas são espaços epistemológicos de convergência entre as ciências da educação e as diversas ciências de referência das disciplinas escolares. Não se trata, evidentemente, de uma relação de subordinação na qual caberia às didáticas aplicar os conhecimentos científicos, mas de TD, nos termos indicados por Petitjean (2008), que se realiza conforme a perspectiva pedagógica assumida.

Isso explica por que a estrutura da disciplina Língua Portuguesa estabelecida na BNCC não apresenta paralelo com as propostas da linguística aplicada nem com a da didática do Grupo de Genebra (DOLZ; SCHNEUWLY, 2004; BRONCKART, 2012; DOLZ; GAGNON; DECÂNDIO, 2014; PIETRO; SCHNEUWLY, 2014), embora tenha vários pontos de contato com essas perspectivas. A principal diferença se refere às concepções pedagógicas assumidas: pedagogia das competências na BNCC, cientificismo na linguística aplicada e interacionismo sociodiscursivo (ISD) no Grupo de Genebra.

\subsection{A ARQUITETURA DA DISCIPLINA LÍNGUA PORTUGUESA NA BNCC}

Na BNCC, a arquitetura da disciplina está em plena sintonia com os princípios apresentados e discutidos na seção anterior. A compreensão de que as competências estão vinculadas às práticas sociais impõe que a linguagem seja compreendida como uma forma de ação. Nesse sentido, o documento adota uma concepção pragmatista de linguagem:

Assume-se aqui a perspectiva enunciativo-discursiva de linguagem, já assumida em outros documentos, como os Parâmetros Curriculares Nacionais (PCN), para os quais a linguagem é uma forma de ação interindividual orientada para uma finalidade específica; um processo de interlocução que se realiza nas práticas sociais existentes numa sociedade, nos distintos momentos de sua história. (BRASIL, 2018, p. 67)

Essa concepção amplifica o princípio básico que orienta a filosofia analítica de Austin (1990), segundo o qual “dizer é fazer”. Nesse contexto, a ideia de interação assume centralidade incontornável, porque vincula a linguagem aos domínios político e cultural. A dimensão científica da linguagem, por sua vez, se distribui por seus níveis de estruturação e suas modalidades: oral, escrita e digital. Não se pode dizer que a BNCC apresenta uma descrição satisfatória desses níveis e modalidades, o que aponta para algumas tarefas urgentes da pesquisa em didática do português.

Quatro aspectos chamam a atenção na caracterização desses níveis. O primeiro diz respeito à designação fono-ortografia, que comporta as relações entre fala e escrita oficial, algo diferente do que ocorre na linguística naturalista, onde apenas os sons da fala são estudados na fonética e na fonologia. O segundo se refere à exclusão do léxico. Causa estranheza a opção pela morfossintaxe quando há um nível sintático separado, no qual seria mais coerente incluir o estudo dos termos oracionais. O terceiro relaciona-se com a inclusão de fenômenos normalmente estudados pela linguística textual no nível sintático. Com efeito, é possível estudar processos referenciais no plano do período, mas tais fenômenos vão além dessa unidade linguística. Finalmente, soa contraditório a BNCC assumir uma perspectiva enunciativo-discursiva de linguagem sem considerar a necessidade de descrever os níveis enunciativo e discursivo.

Uma vez definida a concepção de linguagem e sua natureza, ainda que com limitações, o currículo seleciona as práticas sociais de referência para o ensino. O postulado do texto como unidade de ensino, embora coerente, tem sido recebido de modo equivocado por muitos professores, sobretudo pelos que ainda não compreenderam a nova tipologia dos conteúdos nem seu funcionamento 
nos processos de ensino-aprendizagem. Tais equívocos deságuam na crença de que assumir a centralidade do texto significa prescindir de um trabalho sistemático com os conteúdos gramaticais.

Na BNCC, a ideia de relacionar o desenvolvimento de habilidades ao uso significativo da linguagem por meio de atividades de leitura e produção de textos aciona duas dimensões de práticas, uma social e outra didática. A vertente social se refere aos gêneros textuais e a seus contextos, chamados no documento de campos de atuação. A didática diz respeito às práticas de linguagem que abrigam os conceitos, procedimentos e atitudes necessárias para desenvolver as habilidades de agir através dos gêneros textuais. Como não é possível à escola trabalhar com todos os gêneros que circulam socialmente e todos os campos de atuação, a seleção deve seguir o critério das possibilidades de transferência das habilidades e competências para outros gêneros e contextos não contemplados no currículo, mas que são exigidos na vida social.

Embora os campos de atuação se refiram a esferas de práticas sociais, sua configuração atende a propósitos didáticos, servindo como critérios de agrupamento de gêneros e da progressão das aprendizagens. Essa perspectiva difere da adotada nos PCN, que utilizava os campos discursivos, e do ISD, que utiliza uma concepção própria de tipos de discurso, para agrupar os gêneros. Nessas duas abordagens, o foco recai sobre os fatores linguísticos, enquanto, na BNCC, predomina o critério das práticas sociais de referência, conforme exige a pedagogia das competências.

O agrupamento de gêneros nos campos de atuação observa as fases do desenvolvimento sociocognitivo dos estudantes ao estabelecer uma progressão anual (para cada ano específico) e interanual (ao longo dos níveis de escolaridade) de habilidades de linguagem. Nesse sentido, não são os gêneros em si que definem a progressão das aprendizagens, mas as habilidades associadas a eles.

Os campos de atuação comportam ainda os eixos estruturantes da disciplina: Análise linguística/semiótica, Leitura, Produção Textual e Oralidade, nos quais são alocadas e organizadas as habilidades. Isso significa que cada eixo tem seu próprio conjunto de habilidades associadas aos gêneros de um determinado campo. Além disso, para cada ano de escolaridade, há um número de habilidades comuns aos gêneros de todos os campos de atuação. Isto é, nem todas as habilidades estão ligadas a gêneros específicos, sendo a maior parte delas referentes a aspectos gramaticais. Esse dado aponta para a necessidade de um trabalho sistemático com determinados conteúdos gramaticais importantes para a constituição de vários gêneros como regência e concordância verbal e nominal, colocação pronominal, pontuação, ortografia, emprego de tempos verbais, dentre outros.

Os campos de atuação e seus gêneros estão ligados também à transposição didática da variação linguística em suas relações com as políticas linguísticas. De acordo com Bakhtin (2016), cada esfera da atividade humana determina, ao mesmo tempo, quais gêneros devem circular em seu interior, assim como suas formas composicionais, conteúdos temáticos e estilos. Esse último elemento se refere ao funcionamento da gramática na estruturação textual, observando-se as condições enunciativas e interacionais. A BNCC assume o mesmo entendimento de que os campos de atuação determinam os aspectos formais e funcionais que orientam a circulação de gêneros. Por essa razão, não pode assumir uma perspectiva naturalista de língua, que considera a norma padrão artificial e idealizada, como se ela não tivesse nenhum papel na estruturação de diversas práticas de linguagem, a ponto de precisar ser substituída por uma norma real, a chamada norma culta, conforme o entendimento prevalecente na linguística aplicada.

Relacionar a norma padrão com a concepção pragmatista da linguagem e reconhecer sua importância nas práticas sociais e no ensino não corresponde a tomá-la como um fenômeno homogêneo. Como se depreende da análise de Bourdieu (2008), a língua legítima $^{1}$ (norma padrão) não anula outras formas de expressão, visto que as políticas linguísticas circunscrevem os espaços nos quais essa língua será exigida. Os demais campos terão uma liberdade maior ou menor em relação a essa norma, dependendo dos tipos de interação que mobiliza, se mais ou menos formais. Por exemplo, textos legais e públicos, como o Código do Defesa do Consumidor, não dispõem de liberdade para transgredir as regras da língua legítima. O campo jornalístico pode criar regras próprias através de manuais de estilo e permitir a seus textos certa flexibilidade em relação à norma padrão. Em contrapartida, textos cotidianos, como comentários de Facebook, podem ser totalmente flexíveis diante da língua padronizada.

${ }^{1}$ Entenda-se legítima como revestida de valor legal, ou seja, com força de lei. 
Nesse sentido, verifica-se que a norma padrão não funciona como um tipo de camisa de força aplicada a todos os contextos, mas como uma referência a ser considerada nos vários campos de atividades humanas mediadas pela escrita, seja para observá-la com maior rigor, seja para flexibilizar suas regras, a depender dos objetivos comunicativos e do nível de formalidade das interações. Assim, por sua relevância nas práticas comunicativas institucionalizadas, o acesso à norma padrão deve ser garantido pela escola, instituição responsável por difundi-la (CALVET, 2007).

\subsection{A RELAÇÃO GRAMÁTICA-TEXTO NOS EIXOS ESTRUTURANTES DA DISCIPLINA}

Na pedagogia das competências, os conteúdos escolares são caracterizados pela funcionalidade. A BNCC assume esse princípio ao afirmar que

[...] estudos de natureza teórica e metalinguística - sobre a língua, sobre a literatura, sobre a norma padrão e outras variedades da língua - não devem nesse nível de ensino ser tomados como um fim em si mesmo, devendo estar envolvidos em práticas de reflexão que permitam aos estudantes ampliarem suas capacidades de uso da língua/linguagens (em leitura e em produção) em práticas situadas de linguagem. (BRASIL, 2018, p. 71)

Essa perspectiva contrasta com propostas cientificistas como as de Franchi (2006), Perini (2010), Castilho e Elias (2012), Pilati (2017) e Vieira (2018), que buscam transferir os conhecimentos científicos para o ensino sem as devidas preocupações com o desenvolvimento das capacidades de leitura e produção textual em práticas situadas de linguagem.

O foco na funcionalidade determina também um modelo não linear do trabalho pedagógico envolvendo os quatro eixos, diferentemente do que pretende a proposta do ensino de gramática em três eixos (VIEIRA, 2018). Desse modo, o agrupamento de habilidades em cada um deles deve ser compreendido como um procedimento didático cujo objetivo consiste em organizar os conteúdos e sua progressão, tendo sempre em vista que, em muitos casos, as habilidades dos diferentes eixos se interpenetram.

Não obstante, precisamos admitir que os eixos também possuem habilidades específicas. Os conteúdos tipicamente gramaticais, por exemplo, entram no currículo através do eixo da Análise Linguística/Semiótica, onde se tornam objeto de reflexões. Nos demais eixos, muitas habilidades relacionadas aos saberes gramaticais enfatizam seus usos e funcionamentos na estruturação textual. Cabe ressaltar, no entanto, que as capacidades de linguagem englobadas nos demais eixos não se resumem ao mero tratamento das funcionalidades da gramática, visto que cada um tem seus objetos particulares. Portanto, assumir o princípio da interpenetração dos eixos não significa negar suas particularidades didáticas.

Nesse contexto, a nova tipologia dos conteúdos mobilizada pela pedagogia das competências oferece os fundamentos necessários para orientar a organização e a progressão das aprendizagens, além da forma de interação entre eles. Aqui cabe um esclarecimento importante. A BNCC não menciona explicitamente os três tipos de conteúdos, optando pelo conceito genérico de habilidades. Todavia, como Coll et al. (2008) explicam, as habilidades se subdividem em conceituais, procedimentais e atitudinais. Assim, é mais coerente com a pedagogia das competências considerar que as habilidades de cada eixo são compostas pelos três tipos de conteúdos.

A título de ilustração, analiso a habilidade a seguir, pertencente ao eixo da Produção Textual, ressalvado que a mesma análise podese aplicar aos demais eixos: "(EF08LP03) Produzir artigos de opinião, tendo em vista o contexto de produção dado, a defesa de um ponto de vista, utilizando argumentos e contra-argumentos e articuladores de coesão que marquem relações de oposição, contraste, exemplificação, ênfase”. (BRASIL, 2018, p. 179). Trata-se de uma habilidade vinculada ao campo de atuação jornalístico-midiático, selecionada do $8^{\circ}$ Ano. Nela é possível identificar os seguintes conteúdos:

- conceituais, ligados às noções de artigo de opinião; elementos do contexto de produção; ponto de vista; (contra) argumentos; articuladores de coesão, relações de oposição, contraste, exemplificação e ênfase.

- procedimentais, referentes às atividades de produzir o gênero, defender ponto de vista e (contra-)argumentar. 
- atitudinais, relacionados com os aspectos normativos que envolvem a produção textual, como a observância das normas linguísticas que definem o estilo do gênero, envolvimento com os aspectos morais ligados ao tratamento dos temas do texto, bem como o cuidado com a compreensão do leitor (fatores interacionais).

O detalhamento dos conteúdos permite visualizar a impossibilidade de uma abordagem linear entre eles, uma vez que as noções trabalhadas no plano conceitual exigem a análise do funcionamento delas em textos orais ou escritos. Ou seja, não é possível explicar os conceitos sem demonstrar como eles funcionam. Para isso, é necessário sempre buscar as condições de produção, que vão acionar os conteúdos atitudinais.

Na BNCC, a progressão das habilidades pode-se realizar de maneira longitudinal, recobrindo vários anos ou níveis de escolaridade (Educação Infantil, Ensino Fundamental e Ensino Médio), anualmente (compreendendo a organização progressiva dos conteúdos de um mesmo ano) e entre anos subsequentes - a que fica mais explícita no documento. Um exemplo dessa última modalidade pode ser visto na habilidade a seguir, que amplia, no $9^{\circ}$ Ano, as aprendizagens previstas na habilidade analisada anteriormente: "(EF09LP03) Produzir artigos de opinião, tendo em vista o contexto de produção dado, assumindo posição diante de tema polêmico, argumentando de acordo com a estrutura própria desse tipo de texto e utilizando diferentes tipos de argumentos - de autoridade, comprovação, exemplificação, petição de princípio etc." (BRASIL, 2018, p. 179).

Verificam-se alguns acréscimos em relação ao ano anterior acerca do conhecimento sobre a estrutura ou forma composicional do gênero, das estratégias argumentativas e seus usos. Chama a atenção também o fato de essas estratégias pertencerem ao campo da argumentação retórica e não ao da argumentação na língua, predominante na linguística textual. Uma análise contrastiva dessas duas abordagens pode ser vista em Santos (2017).

Sobre as relações entre gramática e texto, além das situações como as já analisadas, em que o ensino e a aprendizagem se voltam para o funcionamento da gramática em gêneros específicos, considerando suas dimensões conceitual, procedimental e atitudinal, a BNCC reconhece que determinados processos gramaticais (fono-ortográficos, morfossintáticos, semânticos, textuais, enunciativopragmáticos e estilísticos) são comuns a gêneros de todos os campos de atuação.

Essa transversalidade reafirma o caráter funcional dos saberes na pedagogia das competências e reforça o caráter indissociável da relação gramática-texto no âmbito da didática do português. Ademais, afasta definitivamente qualquer desconfiança sobre a relevância dos saberes gramaticais, posto que eles atuam no processo de estruturação textual. No entanto, cumpre reconhecer que ainda não dispomos de uma organização detalhada dos conteúdos, capaz de orientar um ensino articulado e coerente da nova tipologia dos saberes no contexto da pedagogia das competências. Estamos diante de mais um desafio que a didática do português precisa enfrentar com urgência. Apesar disso, a arquitetura geral da disciplina na BNCC representa um importante ponto de partida para as pesquisas.

No documento, embora os saberes gramaticais estejam alocados inicialmente no eixo da Análise Linguística/Semiótica, seus aspectos procedimentais e atitudinais são acionados nos demais eixos, demonstrando a relação dialética entre reflexão e uso da linguagem: a reflexão ajuda a compreender o uso e este ajuda nos processos de reflexão. Ambos são necessários para a utilização consciente da linguagem nas mais diversas situações sociais. Conforme explicitado no documento, "[...] as práticas de leitura/escuta e de produção de textos orais, escritos e multissemióticos oportunizam situações de reflexão sobre a língua e as linguagens de uma forma geral, em que essas descrições, conceitos e regras operam e nas quais serão concomitantemente construídos” (BRASIL, 2018, p. 81).

Essa forma de conceber e organizar os conteúdos revela um continuum na relação gramática-texto e desta com as habilidades dos eixos de Análise Linguística, Leitura, Oralidade e Produção Textual. Consequentemente, esse continuum evidencia também as limitações da linguística aplicada para abordar de modo satisfatório a relação gramática-texto em toda a sua complexidade, seja em razão do viés cientificista que a orienta, seja pela ausência de preocupações com o desenvolvimento sociocognitivo, ou mesmo pelo fato de desconsiderar diversos conteúdos gramaticais em sua investigação. Não se vê em nenhuma gramática científica nem nas 
propostas de ensino que os linguistas apresentam temas como: regras ortográficas, regras de concordância, descrição da norma padrão, pontuação e figuras de linguagem.

\section{CONSIDERAÇÕES FINAIS}

Este texto teve como objetivo analisar a relação gramática-texto na BNCC para demonstrar as diferenças entre as propostas cientificistas da linguística aplicada e a concepção holística da pedagogia das competências. As contribuições do primeiro grupo se subdividem em dois grandes grupos: propostas de especialistas, caracterizadas por tomarem como referência para o ensino uma única disciplina ou paradigma teórico, e propostas inter ou multidisciplinares, que agrupam duas ou mais disciplinas ou paradigmas. Esses dois grupos têm em comum o fato de tratarem do ensino sem considerar os fatores didáticos que atravessam a prática educativa, dentre os quais se destacam a visão global da disciplina, uma compreensão didática dos saberes (transposição didática) e a organização/progressão dos conteúdos, tendo em vista um projeto de desenvolvimento humano para a socialização.

A abordagem didática parte do pressuposto de que os conhecimentos científicos, por estarem subordinados a uma lógica diferente da que a orienta a racionalidade pedagógica, não podem ser objetos de ensino sem passarem por um processo de reelaboração conceitual (transposição didática externa) em conformidade com uma perspectiva pedagógica. No Brasil, a opção das políticas educacionais pela pedagogia das competências apresenta desafios específicos às didáticas específicas em geral e à da língua em particular, considerando o projeto de desenvolvimento humano preconizado no referencial de competências que constituem os objetivos educacionais e o pluralismo teórico orgânico que mobiliza.

A forma de conceber os conteúdos (conceituais, procedimentais e atitudinais) na BNCC, a seleção das práticas sociais de referência (campos de atuação e gêneros textuais), a estruturação da disciplina em quatro eixos organizadores dos conteúdos e da progressão das aprendizagens correspondem à elaboração da didática da Língua Portuguesa no âmbito das políticas educacionais. No entanto, os fundamentos teóricos desses elementos não são apresentados na BNCC. Por essa razão, faz-se necessária a constituição da didática da língua como campo institucionalizado de produção de conhecimento sobre o ensino de linguagem no cenário acadêmico brasileiro.

\section{REFERÊNCIAS}

ANTUNES, I. Gramática contextualizada: limpando “o pó das ideias simples”. São Paulo: Parábola Editorial, 2014.

ASTOLFI, J.-P.; DAROT, E.; GINSBURGER-VOGEL, Y.; TOUSSAINT, J. As palavras-chave da didática das ciências. Trad.: Maria Ludovina Figueiredo. Lisboa: Instituto Piaget, 2002.

ASTOLFI, J.-P.; DEVELAY, M. A didática das ciências. 16. ed. Trad.: Magda Sento Sé Fonseca. Campinas, SP: Papirus Editora, 2012.

AUSTIN, J. L. Quando dizer é fazer. Trad.: Danilo Marcondes de Souza Filho. Porto Alegre: Artes Médicas, 1990.

BAGNO, M. Gramática pedagógica do português brasileiro. São Paulo: Parábola Editorial, 2011.

BAGNO, M. Por que estudar uma gramática brasileira? In: CASSEB-GALVÃO, V.; NEVES, M. H. M. O todo da língua: teoria e prática do ensino de português. São Paulo: Parábola Editorial, 2019.

BAKHTIN, M. Os gêneros do discurso. Trad. Paulo Bezerra. São Paulo: Editora 34, 2016.

BOURDIEU, P. A economia das trocas linguísticas: o que falar quer dizer. Trad. Sérgio Miceli et al. 2. ed. São Paulo: Editora da UNESP. 2008. 
BRASIL. Ministério da Educação. Base Nacional Comum Curricular. Brasília, 2018.

BRONCKART, J-P.; DOLZ, J. A noção de competência: qual é sua pertinência para o estudo da aprendizagem das ações de linguagem. In: DOLZ, J.; OLLAGNIER, E. (Org.). O enigma da competência em educação. Trad. Cláudia Schilling. Porto Alegre: Artmed, 2004, p. 29-46.

BRONCKART, J.-P. Atividade de linguagem, textos e discursos: por um interacionismo sociodiscursivo. 2. ed. Trad. Anna Rachel Machado; Péricles Cunha. São Paulo: EDUC, 2012.

CHAGAS, D. S. Concordância verbal: estratégias para o trabalho com os três eixos para o ensino de gramática. In: VIEIRA, S. R. (Org.). Gramática, variação e ensino: diagnose \& propostas pedagógicas. São Paulo: Blucher, 2018, p. 61-94.

CASTILHO, A. T. Nova gramática do português brasileiro. São Paulo: Contexto, 2010.

CASTILHO, A.; ELIAS, V. M. Pequena gramática do português brasileiro. São Paulo: Contexto, 2012.

CHEV ALlARD, Y. La transposition didactique. Grenoble: La Pensée Sauvage Editions, 1985.

COLL, C.; POZO, J. I.; SARABIA, B.; VALLS, E. Os conteúdos na reforma: ensino e aprendizagem de conceitos, procedimentos e atitudes. Trad. Beatriz Affonso Neves. Porto Alegre: Artmed, 2000.

COLL, C. et al. Psicologia do ensino. Trad. Cristina Maria de Oliveira. Porto Alegre: Artmed, 2008.

DOLZ, J.; SCHNEUWLY, B. Gêneros e progressão em expressão oral e escrita: elementos para reflexões sobre uma experiência suíça (francófona). In: DOLZ, J.; SCHNEUWLY, B. Gêneros orais e escritos na escola. Trad.: Roxane Rojo; Glaís Sales Cordeiro. Campinas, SP: Mercado de Letras, 2004. p. 41-70.

DOLZ, J.; OLLAGNIER, E. O enigma da competência em educação. Trad. Cláudia Schilling. Porto Alegre: Artmed, 2004.

DOLZ, J.; GAGNON, R.; DECÂNDIO, F. R. Uma disciplina emergente: a didática das línguas. In: NASCIMENTO, E. L. Gêneros textuais: da didática das línguas aos objetos de ensino. 2. ed. Campinas, SP: Pontes Editores, 2014, p. 21-50.

FARACO, C. A.; VIEIRA, F. E. Gramáticas em perspectiva. In: FARACO, C. A.; VIEIRA, F. E. (org..). Gramáticas brasileiras: com a palavra, os leitores. São Paulo: Parábola Editorial, 2016. p. 293-318.

FRANCHI, C. Mas o que é mesmo "gramática”? São Paulo: Parábola Editorial, 2006.

GIMENO SACRISTÁN, J. Dez teses sobre a aparente utilidade das competências em educação. In: GIMENO SACRISTÁN, J. et al. Educar por competências: o que há de novo? Trad. Carlos Henrique Lucas Lima. Porto Alegre: Artmed, 2011. p. 13-63.

GIROUX, H. A.; McLAREN, P. Formação do professor como uma contraesfera pública: a pedagogia radical como uma forma de política cultural. In: MOREIRA, A. F. B.; SILVA, T, T. (org.). Currículo, cultura e sociedade. 12. ed. São Paulo: Cortez, 2013.

GERALDI, J. W. Unidades básicas do ensino de português. In: GERALDI, J. W. (org.). O texto na sala de aula. 3. ed. São Paulo: Editora Ática, 2003, p. 59-79.

GHIRALDELLI JR., P. O que é pedagogia. 3. ed. São Paulo: Brasiliense, 2006.

KLEIMAN, A. B.; CAVALCANTI. M. C. (org.). Linguística aplicada: suas faces e interfaces. Campinas, SP: Mercado de Letras, 2007. 
MÉNDEZ, J. M. A. Avaliar a aprendizagem em um ensino centrado nas competências. In: GIMENO SACRISTÁN, J. et al. Educar por competências: o que há de novo? Trad. Carlos Henrique Lucas Lima. Porto Alegre: Artmed, 2011,.p. 233-264.

MENDONÇA, M. Análise linguística no ensino médio: um novo olhar, um outro objeto. In: BUNZEN, C.; MENDONÇA, M. (org.). Português no ensino médio e formação do professor. São Paulo: Parábola Editorial, 2006. p. 199-226.

MOITA LOPES, L. P. Oficina de linguística aplicada: a natureza social e educacional dos processos de ensino-aprendizagem de línguas. Campinas, SP: Mercado de Letras, 1996.

NEVES, M. H. M. Gramática de usos do português. São Paulo: Editora UNESP, 2000.

PERINI, M. A. Gramática do português brasileiro. São Paulo: Parábola Editorial, 2010.

PERRENOUD, P. Desenvolver competências ou ensinar saberes? A escola que prepara para a vida. Trad. Laura Solange Pereira. Porto Alegre: Penso, 2013.

PETITJEAN, A. Importância e limites da noção de transposição didática. Fórum Linguístico, Florianópolis, v. 5, n. 2, p. 83-116, 2008. Disponível em: https://periodicos.ufsc.br/index.php/forum/article/view/1984-8412.2008v5n2p83. Acesso em: 02 dez. 2020.

PIETRO, J.-F.; SCHNEUWLY, B. O modelo didático de gênero: um conceito da engenharia didática. In: NASCIMENTO, E. L. Gêneros textuais: da didática das línguas aos objetos de ensino. 2. ed. Campinas, SP: Pontes Editores, 2014. p. 50-82.

PILATI, E. Linguística, gramática e aprendizagem ativa. 2. ed. Campinas, SP: Pontes Editores, 2017.

POSSENTI, S. Sobre o ensino de português na escola. In: GERALDI, J. W. (org.). O texto na sala de aula. 3. ed. São Paulo: Editora Ática, 2003. p. 32-39.

POZO, J. I. Aprendizes e mestres: a nova cultura da aprendizagem. Trad. Ernani Rosa. Porto Alegre: Artmed, 2002.

SANTOS, M. B. Contra-argumentação e discurso: uma abordagem transdisciplinar. Fórum Linguístico, Florianópolis, v. 14, n. 3, p. 2233-2250, set 2017. Disponível em: https://periodicos.ufsc.br/index.php/forum/article/view/1984-8412.2017v14n3p2233/35134. Acesso em: 02 nov. 2020.

SANTOS, M. B. Sociolinguística, teoria social e padronização linguística. Revista de estudos da linguagem, v. 26, n. 2, p. 687-718, mar. 2018. Disponível em: http://periodicos.letras.ufmg.br/index.php/relin/article/view/12356. Acesso em: 28 nov. 2020.

SANTOS, M. B. Didática da língua e linguística aplicada: duas perspectivas de construção de objetos de ensino. Fórum Linguístico, Florianópolis, v. 16, n. 4, p. 4229-4249, dez. 2019. Disponível em: https://periodicos.ufsc.br/index.php/forum/article/view/19848412.2019v16n4p4229. Acesso em: 02 out .2020.

SOUZA, D. S. Indeterminação do sujeito: proposta pedagógica a partir dos três eixos para o ensino de gramática. In: VIEIRA, S. R. (org.). Gramática, variação e ensino: diagnose \& propostas pedagógicas. São Paulo: Blucher, 2018. p. 121-154.

VIEIRA, S. R. Três eixos para o ensino de gramática. In: VIEIRA, S. R. (org.). Gramática, variação e ensino: diagnose \& propostas pedagógicas. São Paulo: Blucher, 2018. p. 47-60.

ZABALA, A.; ARNAU, L. Como aprender e ensinar competências. Trad. Carlos Henrique Lucas Lima. Porto Alegre: Artmed, 2010. 
ZABALA, A.; ARNAU, L. Métodos para ensinar competências. Trad.: Grasielly Hanke Angeli. Porto Alegre: Penso, 2020.

ZILlES, A. M. S.; FARACO, C. A. (org.). Pedagogia da variação linguística: língua, diversidade e ensino. São Paulo: Parábola Editorial, 2015.

\section{(c) (1) $\circledast$}

Recebido em 07/01/2021. Aceito em 11/02/2021. 